\title{
TUBERCULOSIS AND RECURRENT POSTOPERATIVE WOUND INFECTION
}

Dasharatha Murmu11, Hepsiba Shanthi Kumar², V.S.Shilpa ${ }^{3}$, Kanumury Vandana4, Y.Chennappa Anjanappa ${ }^{5}$.

1. Associate Professor, Department of Obstetrics and Gynaecology (AIIMS), ASRAM Medical College, Eluru.

2. Assistant Professor, Department of Obstetrics and Gynaecology (AIIMS), ASRAM Medical College, Eluru.

3. Department of Obstetrics and Gynaecology (AIIMS), ASRAM Medical College, Eluru.

4. Professor, Department of Obstetrics and Gynaecology(AIIMS), ASRAM Medical College, Eluru.

5. Professor and HOD, Department of Obstetrics and Gynaecology (AIIMS), ASRAM Medical College, Eluru.

\section{CORRESPONDING AUTHOR:}

Dr. Dasharatha Murmu, MD Obstetrics and Gynaecology (AIIMS), Associate Professor, ASRAM Medical College, Eluru, West Godavari, Andhra Pradesh.

Email-dasharathamurmu@gmail.com

\section{HOW TO CITE THIS ARTICLE:}

Dasharatha Murmu, Hepsiba Shanthi Kumar, V.S.Shilpa, Kanumury Vandana, Y. Chennappa Anjanappa. "Tuberculosis and Recurrent Postoperative Wound Infection". Journal of Evolution of Medical and Dental Sciences 2013; Vol2, Issue 23, June 10; Page: 4091-4093.

\begin{abstract}
We report a case of post operative repeated wound infection due to Mycobacterium Tuberculosis. A 25 yr old woman presented to us with watery discharge from Caesarean section wound, done elsewhere 3 months ago. Discharge from the wound showed Acid fast bacilli on Ziehl Neelsen stain, and Histopathology report confirmed tubercular infection. Patient was treated with standard anti tubercular drugs, and is responding well to treatment. A high degree of suspicion is required for exact identification of unusual pathogens in cases of recurrent postoperative wound infection.
\end{abstract}

KEY WORDS: Wound infection, Caesarean section, Tuberculosis

INTRODUCTION: Post operative wound infection is common in routine surgeries. Etiology of infections may vary from patient to patient, hospital to hospital, depending upon the patient's condition and sterility. Most often the infection is due to anaemia, malnutrition, immunodeficiency, diabetes, obesity and during emergency surgeries. In obstetrics the added causes are prolonged labour, prolonged rupture of membrane etc., (1). However wound infections due to Mycobacterium tuberculosis is a very rare entity $(2,3)$. Here is the patient who presented to us with a rare complication of repeated wound infection following LSCS, due to Mycobacterium Tuberculosis.

CASE REPORT: A 25 year old primipara presented to us in the Obstetrics and Gynecology Department of ASRAM Medical college, 3 months after a LSCS done elsewhere, with history of recurrent watery discharge from postoperative wound site (Figure1). There was no history of fever or tenderness over the wound or palpable regional lymph nodes. On exploring the wound, it easily gave way, but the margins of the wound appeared healthy. Daily dressing was done and 
appropriate antibiotics were started simultaneously. Secondary suturing was done after 7 days of daily dressing and patient was discharged well after 10 days. Ten days later patient presented again to the OPD with similar complaints of wound discharge. At this admission, wound was explored and pus discharge was sent for Ziehl Neelsen stain for Acid fast bacilli and tissue from the margins of the wound was sent for histopathological examination. Ziehl Neelsen stain showed positive for AFB and Histopathology report revealed areas of cell necrosis, giant cells and diffuse collection of lymphocytes and granulation tissue which is suggestive of tuberculosis (Figure 2). Blood investigation and Chest $\mathrm{X}$ ray revealed no abnormality. Patient was treated with standard antitubercular drugs.

DISCUSSION: Postoperative recurrent wound infection due to Mycobacterium Tuberculosis is a rare, recognised complication of surgery. Globalisation of tuberculosis with high prevalence is reported in developing countries like Bangladesh, Pakistan and India $(4,5)$. We report a case of post operative repeated wound infection caused by Mycobacterium Tuberculosis. The patient neither had the clinical symptoms of tuberculosis nor a close family member suffered from the disease. So the diagnosis and initiation of treatment was delayed until confirmation of the disease by histopathology. The patient was started on Anti-tubercular treatment (ATT) and is responding to the treatment satisfactorily. Therefore high degree of suspicion is required for exact identification of pathogen, especially in cases of recurrent postoperative wound infections.

ACKNOWLEDGEMENT: First of all we would like to thank our innocent ailing patient who silently contributed to our academic activities and management of unusual complications. We like to thank our Head of the department for his help and valuable suggestion and guidance. We would like to thank pathology and microbiology departments for helping us with the diagnosis.

\section{REFERENCES:}

1. Rahman J, Sultana N, Hasan N et al: Factors of postoperative wound infection in abdominal surgeries of Obstetrics and Gynecology department. Journal of Dhaka Medical college \& Hospital, - 2012: 18(01) 39-42.

2. Damle Ajit S, Karyakarte Rajesh P, Bansal Mangla P: Tuberculous infection in postoperative wound: case report. Ind J Tub, 1995: 42,177.

3. Wang Teresa K, Wang Chi-Fang, Au Wing- Kuk et al: Mycobacterium tuberculosis sterna wound infection after open heart surgery: a case report and review of literature. Diagnostic Microbiology and Infectious disease, 2007: 58; 245-249.

4. Begum H.A: Postoperative tuberculous wound infection: A report of six cases: 2011; $17(02): 49-51$.

5. Global Tuberculosis control. A short update to the 2009 report: WHO:5 


\section{CASE REPORT}

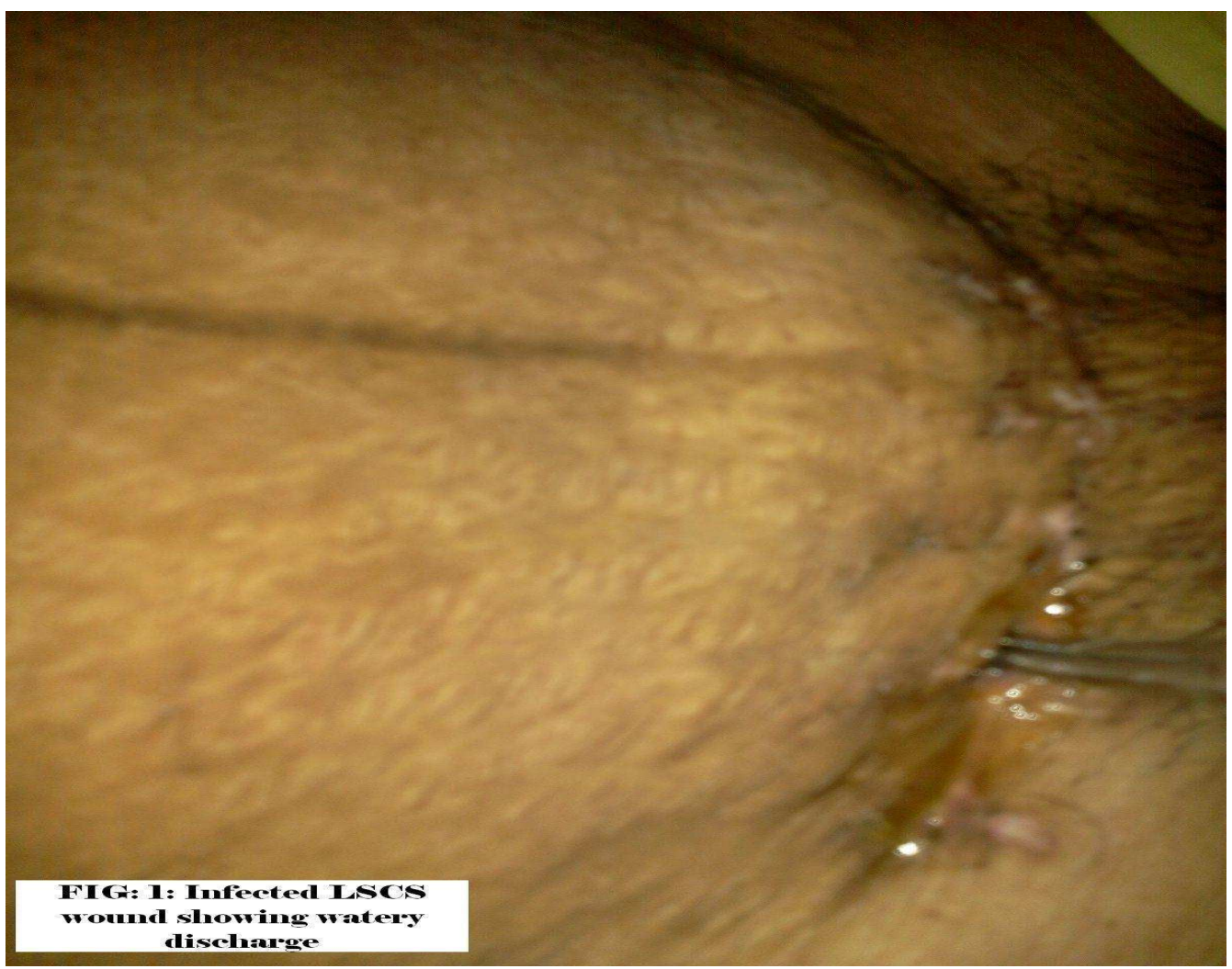

Fig-1 Infected LSCS wound showing watery discharge.

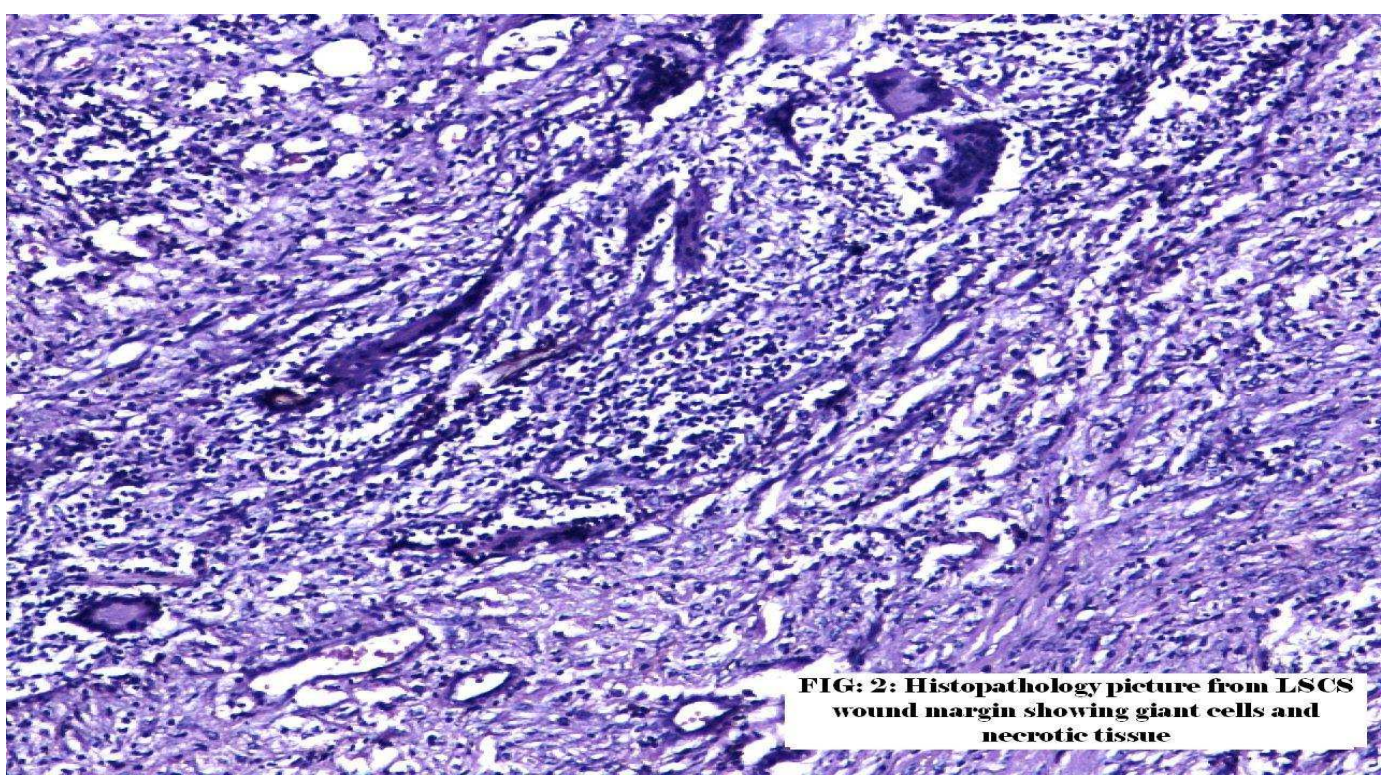

Fig-2 Histopathology Picture from LNCN wound margin showing giant cells and necrotic tissue 